\title{
Mitochondria Determine Response to Anti-PD-1 Therapy: An Evidence-based Hypothesis
}

\author{
By \\ Farzad Taghizadeh-Hesary, M.D \\ Radiation-oncology Department, \\ Shahid Beheshti University of Medical Sciences, Tehran, Iran
}

June 3,2020 


\begin{abstract}
It has been demonstrated that a decrease in cellular adenosine triphosphate (c-ATP) causes cellular dysfunction. T-cells are not an exception. One of their roles is to properly detect and eliminate cancer cells. These processes occur at the expense of ATP. Therefore, it can be concluded that a decrease in C-ATP can defect T-cell function and promote cancer evolution. In this article, we provide a hypothesis to describe the correlation between the expression of PD-1 protein on T-cells and their c-ATP levels. Moreover, we present the possible predictive factors of Anti-PD(L)-1 therapy which has not yet been determined definitely.
\end{abstract}

Keywords: T-lymphocytes; programmed cell death-1; mitochondria; adenosine triphosphate

\title{
Background
}

Nowadays, each human cell is exposed to $10,000-20,000$ DNA mutations per day. Some of these mutations (known as the driver mutation) can induce normal cell transformation to its cancerous counterpart $(1,2)$. Therefore, the efficiency of the immune system to detect the newly developed cancer cell is unassailable. Immune checkpoint inhibitors (ICls) are a novel group of medications that have revolutionized the management of advanced cancers. They eliminate tumors by enhancing the body's own immunity. Tumor microenvironment (TME) contains several supporting cells that protect the cancer cells against the immune system, including myeloidderived suppressor cells (MDSCs) and cancer-associated fibroblasts (CAFs). The ICls work through blocking checkpoint proteins from binding to their partner proteins, therefore, prevent the T-cell to be "turned-off" by cancer cells and its supporters. Nowadays, ICls are the leading choice in advanced and metastatic cancers (3). The ICls targeting the programmed cell death 1 (PD-1) axis are the most encouraging field of research in this context $(4,5)$. They markedly augment T-cell responses in several malignancies. However, the objective response rate of Anti-PD(L)-1 therapy is about $20 \%$ for unknown reasons (6). So far, the predictive factors determining the subset of patients benefit the most from anti-PD(L)-1 inhibitors have remained unclear. Here we present a hypothesis, originating from the concept of cellular energy, that provides the putative mechanism for response to anti-PD-1 inhibitors.

\section{Methods}

In this article we have presented a novel hypothesis to present the key predictors of response to anti-PD-1 monoclonal antibodies (anti-PD-1 mAbs). This hypothesis has originated from the understanding that a decrease in cellular adenosine triphosphate (c-ATP) may induce cellular dysfunction $(7,8)$. In this article, the level of c-ATP is the representative of cellular energy. 


\section{Results}

T-cells play a central role in the prevention and treatment of cancer. When the c-ATP level of T-cells declines to a level that is less than the basal requirements to maintain ion homeostasis for membrane integrity (mediated by the $\mathrm{Na}^{+} / \mathrm{K}^{+}$ATP-dependent pump), the migration, detection, and destruction of newly developed cancer cells become impaired (9). This defect impairs T-cell function in detecting and eliminating the newly formed cancer cell.

According to the literature, there may be a correlation between the metabolic reprogramming of T-cell and their antitumor activity $(9,10)$. Figure 1 summarizes the current findings regarding the alterations in PD-1 expression upon T-cell activation from the cellular energy aspect $(9,11)$. It also demonstrates the trend in the c-ATP level of tumor-infiltrating lymphocytes (TILs) following activation. Naïve T-cells are hypometabolic, and their metabolism is based on the tricarboxylic acid cycle and oxidative phosphorylation (TCA + OXPHOS) (PD-1 is not expressed). Following an initial immune stimulus, a short-term switching of metabolism to glycolysis occurs (PD-1 is expressed), but T-cells are energetically inefficient and need to add TCA + OXPHOS to glycolysis to attain acceptable antitumor activity (PD-1 is not expressed). Then, asymmetric cellular division occurs and the activated T-cells are divided into the effector T-cells $\left(T_{\text {eff }}\right)$ and memory T-cells $\left(T_{m}\right)$ / regulatory $T$-cells $\left(T_{\text {reg }}\right)$. Upon division, $T_{\text {eff }}$ accumulates more cATP because it inherits the metabolically active cytoplasm. However, following counteraction with cancer cells, the c-ATP of $\mathrm{T}_{\text {eff }}$ decreases, and its metabolism is modified into glycolysis when exhaustion occurs (PD-1 is expressed). Exhausted T-cells cannot afford to secrete interferongamma that results in further immunosuppression. In contrast to $T_{\text {eff, }} T_{m}$ (or $T_{\text {reg }}$ ) inherits considerable lipid sources and young mitochondria and maintains the c-ATP level by its active adenosine monophosphate-activated protein kinase (AMPK) (PD-1 is not expressed) (12). PD-1 expression is regulated epigenetically through promoter methylation or histone modification (13). Being such, we speculate that the mediators of TCA+OXPHOS may epigenetically downregulate the PD-1 expression. In summary, we hypothesize that the extent of PD-1 expression is inversely associated with the c-ATP level of TILs. 


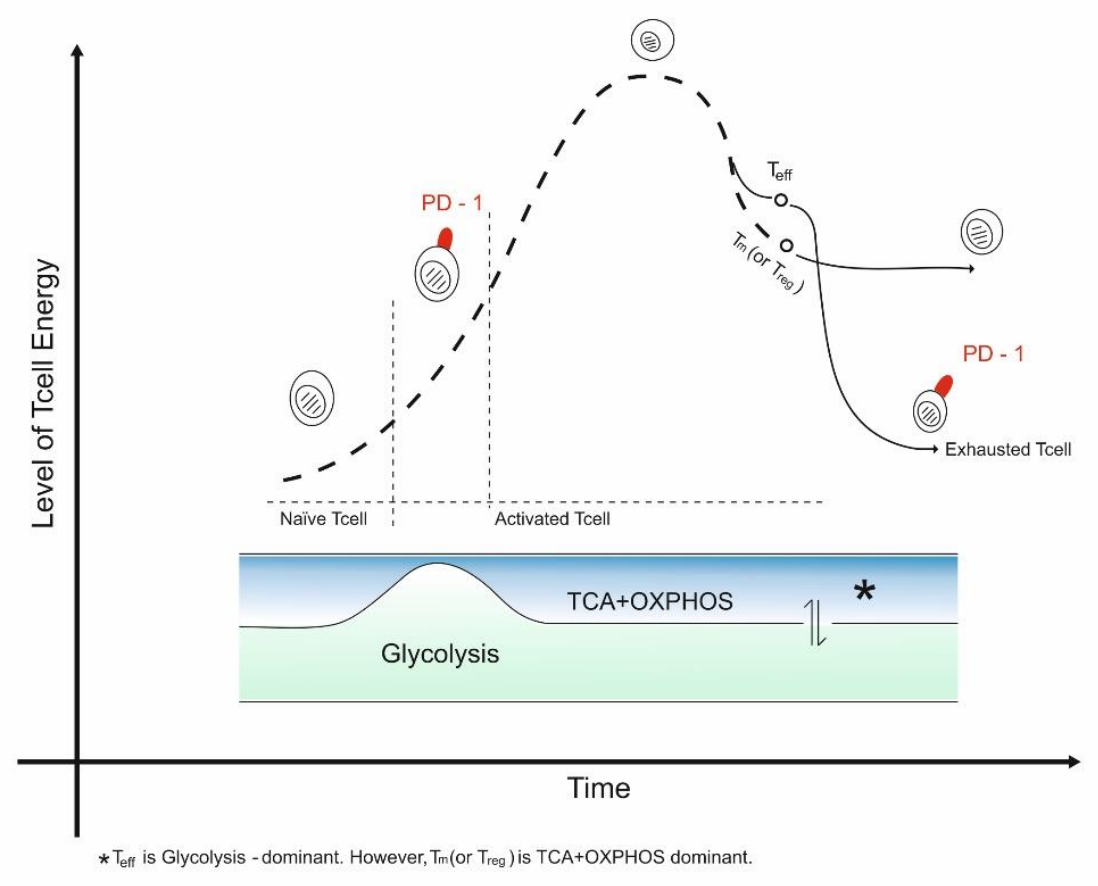

Figure 1. The correlation between the c-ATP level of tumor-infiltrating lymphocytes, type of metabolism, and PD-1 expression.

\section{Discussion}

Currently, the huge challenge for cancer immunotherapy by PD-1 blockade is varied responses in different individuals. Although many patients with advanced cancer benefit from immunotherapy using anti-PD-1 mAb, there are still no effective predictive biomarkers to guide the clinical precision medicine approach and clinical trial design at present.

Table 1 summarizes the prognostic factors of PD-1 expression and predictive factors of response to anti-PD-1 therapy from the cellular energy aspect. In summary, the mitochondria depressing factors (e.g. tobacco smoking, obesity, high SDA-diet, and aging) are associated with enhanced expression of PD-1 on TILs. In contrast, mitochondria boosting factors (e.g. exercise or chemicals such as AMPK activators) are associated with down-regulation of PD-1. 
Table 1| PD-1 expression and response to anti-PD-1 therapy from cellular energy aspect

\begin{tabular}{|c|c|c|c|c|c|c|}
\hline & Title & Clinical findings & Reference & Cellular findings & Reference & $\begin{array}{l}\text { Conclusions from } \\
\text { cellular energy aspect }\end{array}$ \\
\hline $1 \mathrm{~A}$ & $\begin{array}{l}\text { PD-1 expression and } \\
\text { exercise }\end{array}$ & $\begin{array}{l}\text { Sedentary lifestyle is associated } \\
\text { with higher PD-1 expression on } \\
\text { memory } C D 4^{+} T \text { cells }\end{array}$ & (14) & $\begin{array}{lr}\text { Exercise } & \text { improves } \\
\text { lymphocyte } & \text { mitochondrial } \\
\text { functionality } & \\
\end{array}$ & (15) & $\begin{array}{l}\text { Augmentation of mitochondria } \\
\text { improve anti-PD-1 efficacy through } \\
\text { decrease in PD-1 expression }\end{array}$ \\
\hline $1 \mathrm{~B}$ & $\begin{array}{l}\text { Anti-PD-1 and } \\
\text { exercise }\end{array}$ & $\begin{array}{l}\text { Exercise enhances anti-PD-1 } \\
\text { efficacy in murine model }\end{array}$ & (16) & & & \\
\hline $2 \mathrm{~A}$ & $\begin{array}{l}\text { PD-1 expression and } \\
\text { tobacco }\end{array}$ & $\begin{array}{l}\text { Tobacco smokers is associated } \\
\text { with higher PD-1 expression }\end{array}$ & (17) & $\begin{array}{lr}\text { Tobacco smoke } & \text { damages } \\
\text { mitochondria } & \text { of } \\
\text { lymphocytes } & \\
\end{array}$ & (18) & $\begin{array}{l}\text { T-cells with weak mitochondria } \\
\text { respond better to anti-PD-1 due to } \\
\text { already over-expressed PD-1 }\end{array}$ \\
\hline $2 \mathrm{~B}$ & $\begin{array}{l}\text { Anti-PD-1 and } \\
\text { tobacco }\end{array}$ & $\begin{array}{l}\text { anti-PD-1 monotherapy improves } \\
\text { the OS of smokers, but not non- } \\
\text { smokers }\end{array}$ & (19) & & & \\
\hline $3 A$ & $\begin{array}{l}\text { PD-1 expression and } \\
\text { obesity }\end{array}$ & $\begin{array}{l}\text { Obesity is associated with higher } \\
\text { PD-1 expression }\end{array}$ & (20) & $\begin{array}{lr}\text { Obesity } & \text { impairs } \\
\text { mitochondrial } & \text { activity } \\
\text { lymphocytes } & \\
\end{array}$ & (21) & $\begin{array}{l}\text { T-cells with weak mitochondria } \\
\text { respond better to anti-PD-1 therapy } \\
\text { due to already over-expressed PD-1 }\end{array}$ \\
\hline зв & $\begin{array}{l}\text { Anti-PD-1 and } \\
\text { obesity }\end{array}$ & $\begin{array}{l}\text { ORR is higher in overweight/obese } \\
\text { patients }\end{array}$ & (22) & & & \\
\hline $4 \mathrm{~A}$ & $\begin{array}{l}\text { PD-1 expression and } \\
\text { aging }\end{array}$ & $\begin{array}{l}\text { Aging is associated with higher PD- } \\
1 \text { expression }\end{array}$ & (23) & $\begin{array}{l}\text { Mitochondrial function } \\
\text { declines with age }\end{array}$ & (24) & $\begin{array}{l}\text { T-cells with weak mitochondria } \\
\text { respond better to anti-PD-1 due to } \\
\text { already over-expressed PD-1 }\end{array}$ \\
\hline $4 B$ & Anti-PD-1 and aging & $\begin{array}{l}\text { Elderly patients respond better to } \\
\text { anti-PD-1 }\end{array}$ & (25) & & & \\
\hline 5 & $\begin{array}{l}\text { PD-1 expression and } \\
\text { sleep }\end{array}$ & $\begin{array}{l}\text { Obstructive sleep apnea enhances } \\
\text { PD-1 expression }\end{array}$ & (26) & $\begin{array}{l}\text { Obstructive sleep apnea } \\
\text { damages mitochondria }\end{array}$ & (27) & $\begin{array}{l}\text { T-cells with weak mitochondria more } \\
\text { express PD-1 }\end{array}$ \\
\hline & & & & & & \\
\hline 6 & $\begin{array}{l}\text { PD-1 expression and } \\
\text { diet }\end{array}$ & $\begin{array}{l}\text { Western diet (high SDA) increases } \\
\text { PD-1 expression in murine model }\end{array}$ & (28) & $\begin{array}{l}\text { - Mediterranean diet (low } \\
\text { SDA) enhance the immune } \\
\text { system against cancer } \\
-\quad \text { Mediterranean diet } \\
\text { improves mitochondrial } \\
\text { function }\end{array}$ & $\begin{array}{l}(29) \\
(30)\end{array}$ & $\begin{array}{l}\text { Increase in C-ATP decreases PD-1 } \\
\text { expression }\end{array}$ \\
\hline 7 & $\begin{array}{l}\text { Anti-PD-1 and } \\
\text { mitochondria } \\
\text { boosting chemicals }\end{array}$ & $\begin{array}{l}\text { ROSs enhances the therapeutic } \\
\text { efficiency of anti-PD- } 1 \text { therapy } \\
\text { through AMPK expression }\end{array}$ & (31) & AMPK increases the C-ATP & (32) & $\begin{array}{l}\text { Increase in C-ATP is associated with } \\
\text { anti-PD-1 efficacy }\end{array}$ \\
\hline
\end{tabular}

PD-1, Programmed cell death-1; OS, overall survival; ORR, overall response rate; SDA, specific dynamic action; c-ATP, cellular adenosine triphosphate

There are a bunch of TILs in the TME with various c-ATP levels due to different access to nutrients and different levels of encounter with cancer cells. Based on our hypothesis, this difference may result in the varied expression of PD-1 on TILs. If we augment the mitochondrial function of exhausted T-cells, the rise in C-ATP causes down-regulation of PD-1, thus, enhances the antitumor efficacy of TILs. Two recently published papers, showing that enhanced mitochondrial activity has an adjuvant effect for anti-PD-1 immunotherapy, strongly support our hypothesis $(16,31)$.

Reviewing the literature from the cellular energy aspect provides interesting findings. Chamoto et al. demonstrated that mitochondria boosting chemicals (such as ROS, AMPK activators, mTOR activators, and PGC-1 $\alpha$ activators) enhance the antitumor activity of anti-PD-1 mAbs (31). However, the underlying mechanism was not delineated. Based on our hypothesis, the augmentation of mitochondria activity down-regulates the expression of PD-1 on already exhausted TILs. Moreover, an increase in c-ATP enhances their ability to counteract with cancer 
cells and their supporters (33). Therefore, it improves their anti-tumoral activity by either improvement of diagnostic or killing ability.

Obviously, high expression of PD-1 on TILs and PD-L1 on cancer cells, MDSCs, and CAFs predict the better response to anti-PD-1 mAbs (34). However, based on our hypothesis, this is only part of the story. Upon PD-1/PD-L1 interaction, cancer cells and their supporters cause damage to the mitochondria of TILs and switch them to the exhausted form (35). The exhausted TILs cannot afford to efficiently eliminate the cancer cells, even after their recognition through PD-1/PD-L1 axis blockade. Therefore, short-term or limited efficacy of anti-PD-1 mAbs is expected in individuals with already low-energy TILs. In this case, mitochondria boosting approaches may be considered as an adjuvant for anti-PD-1 mAbs by augmenting the energy level of TILs and downregulation of PD-1 protein. This notion explains the Chamoto et al. question that how mitochondria enhancing chemicals improve the response to anti-PD-1 mAbs (31). In contrast, patients with strong mitochondria are expected to have a lower response rate to anti-PD-1 mAbs due to lower expression of PD-1 protein. However, the high-energy group has a potentially better prognosis because of a more efficient diagnosis and elimination of cancer cells due to less expression of PD-1 protein and less interaction with PD-L1 protein, respectively.

Our hypothesis answers the following questions, how exercise enhances the response to antiPD-1 mAb? Why cigarette smokers respond better to anti-PD-1 therapy? Why overweight/obese patients have more response rates to anti-PD-1 mAb? And how aging is a good predictive factor for anti-PD-1 therapy?

There are several approaches to improve c-ATP. Most of them are accessible through a change in lifestyle. First, regular exercise improves mitochondrial respiratory capacity through an increase in PGC-1 $\alpha$ (36). Smoking cessation is the second approach to improve mitochondrial capacity and improvement in c-ATP (37). Third, consuming foods with low specific dynamic action (SDA), as the energetic budget for consuming food, can potentially boost the immune system through improving the c-ATP. Recent studies have demonstrated the effect of low-SDA meals on the up-regulation of the innate immune system in corn snakes (38). Fourth, improvement in sleep quality can potentially improve the mitochondrial bioenergetic capacity (39). As demonstrated by Chamoto et al. several chemicals can also improve the mitochondrial activity, including ROS, uncouplers, AMPK activators, mTOR activators, and PGC-1 $\alpha$ activators (31).

Further clinical trials can use these approaches to improve the efficacy of anti-PD-1 therapy. Moreover, future studies may consider this hypothesis to better determine the predictive factors of response to anti-PD-1 therapy.

\section{Conclusion}

Our hypothesis demonstrated the correlation between the c-ATP level of TILs and their antitumor activity. It also demonstrated a correlation between PD-1 expression on T-cells and the level of c-ATP. These correlations may simply occur coincidentally or may have a causal relationship. Further studies are needed to clarify the possible link. 


\section{References}

1. Speicher MR. Searching for cancer vulnerabilities amid genetic chaos. Springer; 2017.

2. Akbari H, Taghizadeh-Hesary F, Heike Y, Bahadori M. Cell Energy: A New Hypothesis in Decoding Cancer Evolution. Archives of Iranian Medicine (AIM). 2019;22(12).

3. Lesterhuis WJ, Bosco A, Millward MJ, Small M, Nowak AK, Lake RA. Dynamic versus static biomarkers in cancer immune checkpoint blockade: unravelling complexity. Nature Reviews Drug Discovery. 2017;16(4):264.

4. Boussiotis VA. Molecular and biochemical aspects of the PD-1 checkpoint pathway. New England Journal of Medicine. 2016;375(18):1767-78.

5. Palucka AK, Coussens LM. The basis of oncoimmunology. Cell. 2016;164(6):1233-47.

6. Carretero-González A, Lora D, Ghanem I, Zugazagoitia J, Castellano D, Sepúlveda JM, et al. Analysis of response rate with ANTI PD1/PD-L1 monoclonal antibodies in advanced solid tumors: a meta-analysis of randomized clinical trials. Oncotarget. 2018;9(9):8706.

7. Avicenna. A treatise on the Canon of medicine of Avicenna, incorporating a translation of the first book: London : Luzac \&amp; co., 1930.; 1930.

8. Johnson TA, Jinnah H, Kamatani N. Shortage of Cellular ATP as a Cause of Diseases and Strategies to Enhance ATP. Frontiers in pharmacology. 2019;10:98.

9. Herbel C, Patsoukis N, Bardhan K, Seth P, Weaver JD, Boussiotis VA. Clinical significance of T cell metabolic reprogramming in cancer. Clinical and translational medicine. 2016;5(1):29.

10. Bai J, Gao Z, Li X, Dong L, Han W, Nie J. Regulation of PD-1/PD-L1 pathway and resistance to PD1/PD-L1 blockade. Oncotarget. 2017;8(66):110693.

11. Nishimura H, Agata Y, Kawasaki A, Sato M, Imamura S, Minato N, et al. Developmentally regulated expression of the PD-1 protein on the surface of double-negative (CD4-CD8-) thymocytes. International immunology. 1996;8(5):773-80.

12. Le Bourgeois T, Strauss L, Aksoylar H-I, Daneshmandi S, Seth P, Patsoukis N, et al. Targeting T cell metabolism for improvement of cancer immunotherapy. Frontiers in oncology. 2018;8:237.

13. Bally AP, Austin JW, Boss JM. Genetic and epigenetic regulation of PD-1 expression. The Journal of Immunology. 2016;196(6):2431-7.

14. Gustafson MP, DiCostanzo AC, Wheatley CM, Kim C-H, Bornschlegl S, Gastineau DA, et al. A systems biology approach to investigating the influence of exercise and fitness on the composition of leukocytes in peripheral blood. Journal for immunotherapy of cancer. 2017;5(1):30.

15. Tsai H-H, Chang S-C, Chou C-H, Weng T-P, Hsu C-C, Wang J-S. Exercise training alleviates hypoxiainduced mitochondrial dysfunction in the lymphocytes of sedentary males. Scientific reports. 2016;6:35170.

16. Martín-Ruiz A, Fiuza-Luces C, Rincón-Castanedo C, Fernández-Moreno D, Gálvez BG, MartínezMartínez $\mathrm{E}$, et al. Benefits of exercise and immunotherapy in a murine model of human non-small-cell lung carcinoma. Exercise Immunology Review. 2020;26:100-15.

17. Valiathan R, Miguez MJ, Patel B, Arheart KL, Asthana D. Tobacco smoking increases immune activation and impairs T-cell function in HIV infected patients on antiretrovirals: a cross-sectional pilot study. Plos one. 2014;9(5).

18. Miró O, Alonso JR, Jarreta D, Casademont J, Urbano-Márquez A, Cardellach F. Smoking disturbs mitochondrial respiratory chain function and enhances lipid peroxidation on human circulating lymphocytes. Carcinogenesis. 1999;20(7):1331-6.

19. Mo J, Hu X, Gu L, Chen B, Khadaroo PA, Shen Z, et al. Smokers or non-smokers: who benefits more from immune checkpoint inhibitors in treatment of malignancies? An up-to-date meta-analysis. World journal of surgical oncology. 2020;18(1):15. 
20. Wang Z, Aguilar EG, Luna JI, Dunai C, Khuat LT, Le CT, et al. Paradoxical effects of obesity on T cell function during tumor progression and PD-1 checkpoint blockade. Nature medicine. 2019;25(1):141-51.

21. Ederlé C, Charles A-L, Khayath N, Poirot A, Meyer A, Clere-Jehl R, et al. Mitochondrial Function in Peripheral Blood Mononuclear Cells (PBMC) Is Enhanced, Together with Increased Reactive Oxygen Species, in Severe Asthmatic Patients in Exacerbation. Journal of clinical medicine. 2019;8(10):1613.

22. Cortellini A, Bersanelli M, Buti S, Cannita K, Santini D, Perrone F, et al. A multicenter study of body mass index in cancer patients treated with anti-PD-1/PD-L1 immune checkpoint inhibitors: when overweight becomes favorable. Journal for immunotherapy of cancer. 2019;7(1):57.

23. Whisler RL, Chen M, Liu B, Newhouse YG. Age-related impairments in TCR/CD3 activation of ZAP70 are associated with reduced tyrosine phosphorylations of $\zeta$-chains and p59fyn/p56lck in human T cells. Mechanisms of ageing and development. 1999;111(1):49-66.

24. Chistiakov DA, Sobenin IA, Revin VV, Orekhov AN, Bobryshev YV. Mitochondrial aging and agerelated dysfunction of mitochondria. BioMed research international. 2014;2014.

25. Kugel CH, Douglass SM, Webster MR, Kaur A, Liu Q, Yin X, et al. Age correlates with response to anti-PD1, reflecting age-related differences in intratumoral effector and regulatory T-cell populations. Clinical Cancer Research. 2018;24(21):5347-56.

26. Cubillos-Zapata C, Almendros I, Díaz-García E, Toledano V, Casitas R, Galera R, et al. Differential effect of intermittent hypoxia and sleep fragmentation on PD-1/PD-L1 upregulation. Sleep. 2020;43(5):zsz285.

27. Lacedonia D, Carpagnano GE, Crisetti E, Cotugno G, Palladino GP, Patricelli G, et al. Mitochondrial DNA alteration in obstructive sleep apnea. Respiratory research. 2015;16(1):47.

28. Yu S, Wu X, Shi Z, Huynh M, Jena PK, Sheng L, et al. Diet-induced obesity exacerbates imiquimodmediated psoriasiform dermatitis in anti-PD-1 antibody-treated mice: Implications for patients being treated with checkpoint inhibitors for cancer. Journal of Dermatological Science. 2020.

29. Soldati L, Di Renzo L, Jirillo E, Ascierto PA, Marincola FM, De Lorenzo A. The influence of diet on anti-cancer immune responsiveness. Journal of translational medicine. 2018;16(1):75.

30. Caplliure-Llopis J, Peralta-Chamba T, Carrera-Juliá S, Cuerda-Ballester M, Drehmer-Rieger E, López-Rodriguez $\mathrm{MM}$, et al. Therapeutic alternative of the ketogenic Mediterranean diet to improve mitochondrial activity in Amyotrophic Lateral Sclerosis (ALS): A Comprehensive Review. Food Science \& Nutrition. 2019.

31. Chamoto K, Chowdhury PS, Kumar A, Sonomura K, Matsuda F, Fagarasan S, et al. Mitochondrial activation chemicals synergize with surface receptor PD-1 blockade for T cell-dependent antitumor activity. Proceedings of the National Academy of Sciences. 2017;114(5):E761-E70.

32. Garcia D, Shaw RJ. AMPK: Mechanisms of Cellular Energy Sensing and Restoration of Metabolic Balance. Mol Cell. 2017;66(6):789-800.

33. Desdín-Micó G, Soto-Heredero G, Mittelbrunn M. Mitochondrial activity in T cells. Mitochondrion. 2018;41:51-7.

34. Ren D, Hua Y, Yu B, Ye X, He Z, Li C, et al. Predictive biomarkers and mechanisms underlying resistance to PD1/PD-L1 blockade cancer immunotherapy. Molecular cancer. 2020;19(1):1-19.

35. Ogando J, Sáez ME, Santos J, Nuevo-Tapioles C, Gut M, Esteve-Codina A, et al. PD-1 signaling affects cristae morphology and leads to mitochondrial dysfunction in human CD8+ T lymphocytes. Journal for immunotherapy of cancer. 2019;7(1):151.

36. Burelle $Y$, Hochachka PW. Endurance training induces muscle-specific changes in mitochondrial function in skinned muscle fibers. Journal of Applied Physiology. 2002;92(6):2429-38.

37. Malińska D, Więckowski MR, Michalska B, Drabik K, Prill M, Patalas-Krawczyk P, et al. Mitochondria as a possible target for nicotine action. Journal of bioenergetics and biomembranes. 2019;51(4):259-76. 
38. Luoma RL, Butler MW, Stahlschmidt ZR. Plasticity of immunity in response to eating. Journal of Experimental Biology. 2016;219(13):1965-8.

39. Rodrigues NR, Macedo GE, Martins IK, Gomes KK, de Carvalho NR, Posser T, et al. Short-term sleep deprivation with exposure to nocturnal light alters mitochondrial bioenergetics in Drosophila. Free Radic Biol Med. 2018;120:395-406.

\section{List of abbreviations}

AMPK Adenosine monophosphate-activated protein kinase

ATP Adenosine triphosphate

CAF Cancer-associated fibroblast

ICl Immune checkpoint inhibitor

MDSC Myeloid-derived suppressor cell

mTOR Mammalian target of rapamycin

PGC-1 $\alpha$ Proliferator-activated receptor gamma coactivator-1 $\alpha$

PD-1 Programmed death-1

PD-L1 Programmed death-ligand 1

SDA Specific dynamic action

Teff Effector T-cell

$\mathrm{T}_{\mathrm{m}} \quad$ Memory T-cell

TME Tumor microenvironment

$T_{\text {reg }} \quad$ Regulatory T-cell 